\title{
Phytochemical compounds and antioxidant activity of Coleus tuberosus flesh and peel on different solvent
}

\author{
${ }^{1}$ Nugraheni, M., ${ }^{2}$ Santoso, U. and ${ }^{3}$ Windarwati \\ ${ }^{1}$ Department of Culinary Art Education, Engineering Faculty, Yogyakarta State University, Indonesia \\ ${ }^{2}$ Department of Food Science, Faculty of Agricultural Technology, Gadjah Mada University, Indonesia \\ ${ }^{3}$ Dr. Sardjito General Hospital, Yogyakarta, Health Ministry of Republic Indonesia
}

Article history:

Received: 25 May 2018

Received in revised form: 15 July 2018

Accepted: 24 July 2018

Available Online: 9 August 2018

\section{Keywords:}

Total phenolic,

Flavonoid,

Coleus tuberosus

\section{DOI:}

https://doi.org/10.26656/fr.2017.2(5).098

\begin{abstract}
Three different solvents were used to extract the phytochemical compounds in the peel and flesh of Coleus tuberosus. The results of extraction with different solvents were compared based on the levels of phytochemicals compounds and its antioxidant activity. Extraction of bioactive compounds was done by the maceration method using methanol, ethyl acetate, and chloroform for seven days at a ratio of 1:5 (w/v). Determination of total phenolic contents and flavonoids was conducted via spectrophotometric method. Antioxidant activity was evaluated based on DPPH, peroxide value and TBA value. The results showed that the methanol solvent extracted higher total phenolic and flavonoids compounds than the ethyl acetate and chloroform. The antioxidant activity of methanol extracts was higher compared to ethyl acetate and chloroform extracts for both flesh and peel of $C$. tuberosus. The extract of the peel of $C$. tuberosus had antioxidant activity higher compared to the flesh extract with the use of methanol, ethyl acetate or chloroform as solvent. There was a positive and significant correlation between total phenolic and flavonoids content against DPPH and a negative and significant correlation with peroxide and TBA value.
\end{abstract}

\section{Introduction}

Coleus tuberosus include local tubers that belong to Lamiaceae family, sub nepetoideae family, tribe Ocimeae and has an essential role in food security that contains some types of bioactive compounds known to function as antioxidants and anti-cancer. The bioactive compounds identified from $C$. tuberosus were triterpenic acid including ursolic acid and oleanolic acid, total phenol and flavonoid (Mathe et al., 2007; Nugraheni et al., 2011). Some research showed that bioactive compounds in fruits and vegetables namely total phenolic content, flavonoid, and triterpenic acid have the ability as an antioxidant (Fu et al., 2017; Shiraishi et al., 2018). The potential of an antioxidant is associated with the ability to free scavenging radicals, donates hydrogen atoms or electrons and chelates metal to decrease the risk of degenerative disease such as cancer and diabetes mellitus (Wang et al., 2018; Arif et al., 2018).

The effort to obtain natural antioxidants from plants, fruits and vegetables can be performed by several methods of solvent extraction, maceration, supercritical fluid extraction and so on. However, the number of bioactive compounds and antioxidant activity does not only depend on the extraction process but, it is also influenced by the type of solvent used. The extraction process aims to get certain parts of ingredients that contain bioactive compounds (Azmir et al., 2013; Resende et al., 2017). The extraction method used by many is distillation and solvent extraction. Solvent extraction can be done in the two ways: aqueous phase and organic phase. Extraction of the aqueous phase is done using water as solvent, while the organic phase uses organic solvent (Bodoira et al., 2017; Chen et al., 2017).

Based on the polarity, the type of solvent and the method may affect their ability to prevent oxidation. If the solvent is polar, it is able to extract the alkaloid compounds, total phenolic, flavonoids, carotenoids, tannin, sugar, amino acids, and glycosides content. The objectives of this research were to identify the phytochemical compounds and to evaluate the antioxidant activity of $C$. tuberosus flesh and peel using different solvents. 


\section{Materials and methods}

\subsection{Chemicals and reagents}

The chemical materials used were methanol, ethyl acetate, distilled water, Folin-Ciocalteu reagent, $\mathrm{NaCO}_{3}$, and gallic acid, $\mathrm{NaNO}_{2}, \mathrm{AlCl}_{3} \cdot 6 \mathrm{H}_{2} \mathrm{O}, \mathrm{NaOH}, \mathrm{BHT}, 1,1$ diphenyl-2-picrylhydrazyl (DPPH) (Sigma Aldrich) linoleic acid, chloroform (HPLC grade), quercetin (Sigma Aldrich) as standard.

\subsection{Sample preparation}

C. tuberosus peel was separated from the flesh using a peeler. The flesh was then thinly sliced with a thickness of 1-1.5 $\mathrm{mm}$. The flesh and peel were examined as a subject separately. The flesh and peel of C. tuberosus were dried with a cabinet drier at a temperature of $40^{\circ} \mathrm{C}$ for $24 \mathrm{hrs}$. After drying, the dried peel and flesh was milled into flour and sifted using a Tyler sieve 80 mesh before storing at $-20^{\circ} \mathrm{C}$ for further analysis.

\subsection{Extraction process}

The peel and flesh flour were subjected to extraction by maceration method using solvents methanol, ethyl acetate, and chloroform. The ratio of flour to solvent was 1:5 (w/v). The process of maceration was carried out for seven days. After seven days, the solution was filtered with Whatman No. 1 filter paper and evaporated using a rotavapor to remove the solvent. The extracts were then stored at $-22^{\circ} \mathrm{C}$.

\subsection{Determination of total phenolic content}

The total phenolic content of the different solvents, i.e., methanol, ethyl acetate and chloroform, extract of $C$. tuberosus flour were determined using spectrophotometric method (Singleton et al., 1999). At a concentration of $100 \mathrm{mg} / \mathrm{L}, 0.2 \mathrm{~mL}$ of the extract were added to $2.5 \mathrm{~mL}$ of $10 \%$ Folin-Ciocalteu reagent and 2 $\mathrm{mL}$ of $7.5 \% \mathrm{Na}_{2} \mathrm{CO}_{3}$. The mixture was incubated for 15 mins at $45^{\circ} \mathrm{C}$. The absorbance of the solution was measured using a spectrophotometer at a wavelength of $765 \mathrm{~nm}$. The content of total phenolic was expressed as milligrams ( $\mathrm{mg}$ ) of gallic acid equivalent per gram of the dried extract (mg of GAE/g extract). Each sample was analyzed in triplicate to obtain an average value.

\subsection{Determination of total flavonoids content}

The analysis of the levels of flavonoids was done with spectrophotometric method (Quettier-Deleu et al., 2000). At a concentration of $1000 \mathrm{mg} / \mathrm{L}, 1 \mathrm{~mL}$ of the aqueous solution extract was added to $1 \mathrm{~mL} 2 \% \mathrm{AlCl}_{3}$ dissolved with ethanol $50 \%$. At the twentieth minute of incubation, the mixture was homogenized using the vortex and the absorbance was measured at $415 \mathrm{~nm}$. The analysis was done in triplicate measurements, and the content of flavonoids was expressed as quercetin equivalents ( $\mathrm{mg}$ of quercetin/g of extract).

\subsection{Antioxidant activity evaluation: DPPH method}

Evaluation of antioxidant activity was performed with the DPPH method (Singh et al., 2009). The extracts were aliquoted $(40 \mu \mathrm{g} / \mathrm{mL})$ and mixed with $2 \mathrm{~mL}$ of DPPH (0.1 mM in methanol solution). The solution was homogenized with vortex, which was stand for $30 \mathrm{mins}$ at room temperature, protected from light. The absorbance of the solution was measured at a wavelength of $517 \mathrm{~nm}$. The butylated hydroxytoluene (BHT) concentration at $40 \mu \mathrm{g} / \mathrm{ml}$ was used as the comparative compound. The radical scavenging activity was calculated using the formula:

$$
\frac{A_{0}-A_{1}}{A_{0}} \times 100 \%
$$

Where $A_{0}$ is the absorbance of the control (without the extract), and $\mathrm{A}_{1}$ is the absorbance of $\mathrm{BHT}$ or the extract.

\subsection{Antioxidant activity evaluation: peroxide value}

The peroxide value was determined using the ferric thiocyanate (FTC) method (Zahin et al., 2009) for antioxidant activity. The extracts $(40 \mu \mathrm{g} / \mathrm{mL})$ were mixed with BHT $(40 \mu \mathrm{g} / \mathrm{mL})$ in absolute ethanol, $4.1 \mathrm{~mL}$ of $2.5 \%$ linoleic acid in absolute ethanol, $8.0 \mathrm{~mL}$ of 0.05 $\mathrm{M}$ phosphate buffer ( $\mathrm{pH} 7.0)$ and $3.9 \mathrm{~mL}$ of water was placed in a screw cap vial and incubated at $40^{\circ} \mathrm{C}$ in dark. To $0.1 \mathrm{~mL}$ of this solution was added $9.7 \mathrm{~mL}$ of $75 \%$ ethanol and $0.1 \mathrm{~mL}$ of $30 \%$ ammonium thiocyanate. Precisely after 3 mins, $0.1 \mathrm{~mL}$ of $0.02 \mathrm{M}$ ferrous chloride in $3.5 \% \mathrm{HCl}$ was added to the reaction mixture and the absorbance of was measured at $500 \mathrm{~nm}$ at $24 \mathrm{hrs}$ interval until five days. All measurements were carried out in triplicate. The peroxide value was expressed as milliequivalent per $1000 \mathrm{~g}$ of sample.

\subsection{Antioxidant activity evaluation: thiobarbituric acid} (TBA)

The antioxidant activity evaluation with thiobarbituric acid (TBA) was referred to Zahin et al. (2009). The sample solution $(1 \mathrm{~mL})$ was added with 2 $\mathrm{mL}$ of $0.67 \%$ 2-thiobarbituric acid and $2 \mathrm{~mL}$ of $20 \%$ trichloroacetic acid, as prepared in the FTC method. The mixture was placed in a boiling water bath. After cooling, was centrifuged at $3000 \mathrm{rpm}$ for 20 mins. The absorbance of the supernatant was measured at $552 \mathrm{~nm}$. The antioxidant activity was based on the absorbance on the final day of the FTC method. Malonaldehyde concentration calculated with standard 1,1,3,3tetraethoxypropane (TEP). The standard curve used malonaldehyde 1,1,3,3-tetraethoxypropane solution 
(TEP). TBA value stated was expressed as $\mathrm{mg}$ MDA/1000 $\mathrm{g}$ of the sample.

\subsection{Statistical analysis}

The correlation between the treatment (the relationship between total phenolics content components with the level of total and total antioxidant activity and phenolic content relationship with antioxidant activity) tested with Pearson correlation bivariate using Statistical Product and Service Solution (SPSS) 12.0 for windows.

\section{Results and discussion}

\subsection{Levels of phytochemicals}

Polarity differences can give different results in the extract of phytochemical compounds in vegetables and fruits. The necessary efforts to the selection of the type of solvent compound to obtain optimum results on the type of different bioactive compounds are required. The extraction process of total flavonoids and phenolic content were done using three solvents namely methanol, ethyl acetate, and chloroform. The use of different solvents was to find out the type of solvent that can extract the optimum of total phenols and flavonoids level. The extraction was done by the maceration method for seven days.

Table 1. The levels of total phenols and total flavonoids on $C$. tuberosus flesh and peel in different solvent

\begin{tabular}{lcc}
\hline \multicolumn{1}{c}{ Solvent } & TPC $(\mathrm{mg} \mathrm{GAE} / \mathrm{g})$ & TFC $(\mathrm{mgQCE} / \mathrm{g})$ \\
\hline Peel \\
\hline Ethyl acetate extract & $7.73 \pm 0.08 \mathrm{fC}$ & $8.55 \pm 0.07 \mathrm{fC}$ \\
Chloroform extract & $1.78 \pm 0.03 \mathrm{aA}$ & $1.61 \pm 0.09 \mathrm{cA}$ \\
\hline \multicolumn{3}{c}{ Flesh } \\
\hline Methanol extract & $7.24 \pm 0.10 \mathrm{eB}$ & $2.31 \pm 0.13 \mathrm{dC}$ \\
Ethyl acetate extract & $7.14 \pm 0.12 \mathrm{~dB}$ & $1.45 \pm 0.17 \mathrm{bB}$ \\
Chloroform extract & $1.84 \pm 0.08 \mathrm{bA}$ & $0.27 \pm 0.03 \mathrm{aA}$ \\
\hline
\end{tabular}

Different letters (a-f) within the column indicate significant differences in flesh and peel of $C$. tuberosus on different solvent at $\mathrm{P}<0.05$.

Different capital letters (A-C) within the column in $C$. tuberosus flesh or peel indicate significant differences in different solvents at $\mathrm{P}<0.05$.

The levels of total phenolic and flavonoids of the extracts of $C$. tuberosus peel and flesh with different solvents are shown in Table 1 . The peel extract contents of total phenolic and flavonoids were higher than the flesh extract of $C$. tuberosus. The results were in agreement with the research conducted by AhmadiAlfazi et al. (2015) and Saidani et al. (2017). Total phenolics compounds acres fills up in higher amounts extracted with a more polar solvent. Based on this result, it was shown that the number of total phenolic and flavonoids extracted using methanol was higher than the extraction using ethyl acetate and chloroform. The higher number of total phenolic and flavonoids extracted using methanol indicates that the total phenolic content and flavonoids have polar non-polar bonds than a tendency. Many research also showed that the extraction of total phenolic and flavonoids using polar solvents can provide significant results than using a non-polar solvent (Do et al., 2014; Pintac et al., 2018).

\subsection{Antioxidant activity evaluation via DPPH method}

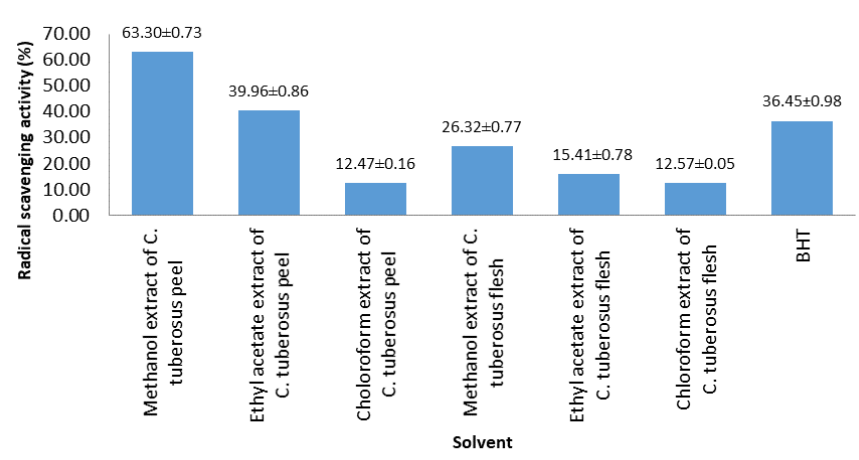

Figure 1. Antioxidant activity of C. tuberosus peel and flesh with different solvent based on DPPH method

DPPH method is used to evaluate the activity of antioxidant a substance. It was evaluated by measuring scavenging free radicals using a synthetic radical which is 1, 1, 2, 2- diphenyl picrylhydrazin (DPPH). The DPPH changes are detected by the decrease of the DPPH absorbance in the solution when added with antioxidant compounds. Figure 1 shows the antioxidant activity value measured using the DPPH method. The significant decrease in absorbance indicates a higher antioxidant activity of the solution. The methanol extract which contains higher total phenolic and flavonoids extract than that of ethyl acetate and chloroform extract demonstrated greater antioxidant activity when compared to the antioxidant activity of the extract of ethyl acetate and chloroform (Figure 1).

Figure 1 also shows the tendency of peel had a higher antioxidant activity than the flesh of $C$. tuberosus. The different antioxidant activity relates to the difference between the content of total phenolics and flavonoids in the flesh and peel (Table 1). Antioxidant activity differences on the flesh and peel can be related to the differences in the bioactive compounds (Wang et al., 2012; Raudone et al., 2017). Medini et al. (2014) stated that total phenolics and flavonoids have an excellent free radical scavenging ability and can be used as a radical scavenger, acting possibly as a primary antioxidant.

This research proves that the percentage of radical scavenging activity on the peel of $C$. tuberosus is higher than the flesh. The peel contained more bioactive compounds which have the greater ability to transfer 
hydrogen atoms to DPPH free radicals to form a stable compound diphenyl picrylhydrazyl stable. The higher diphenyl picrylhydrazyl that formed shows higher antioxidant capability, especially on the scavenging of free radicals. Antioxidant activity differences were allegedly caused by bioactive compounds that are in the peel and flesh of $C$. tuberosus, suppose maslinic acid and phytosterol (stigmasterol, beta-sitosterol, campesterol) (Fu et al., 2014; Prasad et al., 2016).

\subsection{Antioxidant analysis with peroxide value method}

Antioxidant activity with peroxide value method was used to find out the capabilities of the peel and flesh extract of C. tuberosus in different solvents in inhibiting the lipids peroxidation. Peroxide is formed as a result of the process of oxidation that occurs in the oil during the incubation period (Halvorsen et al., 2011). Table 2 shows that the bioactive compounds found in extract peel and flesh of methanol, ethyl acetate, and chloroform can reduce the radical hydroxyl, radical peroxide, and super peroxide on the system of an emulsion to inhibit oxidation. Antioxidants neutralize free radicals by giving one of its electrons to the free radicals and transforms into non-radical forms. The addition of antioxidants can inhibit the rate of increase in the number of peroxides.

Peroxide value in the linoleic system increased with increasing incubation time of the peel or flesh of methanol, ethyl acetate, chloroform extract of $C$. tuberosus, and BHT. Peroxide number in the system that given methanol, ethyl acetate, chloroform extract of $C$. tuberosus peel or flesh and BHT were lower than controls. This research proved that the extract of methanol, ethyl acetate, chloroform of C. tuberosus extract and BHT could suppress the formation of linoleic acid hydroperoxide.

The methanol extract of C. tuberosus flesh or peel can suppress peroxide value higher than chloroform and ethyl acetate extract. The ability to suppress peroxide value was shown by the lowest of a number of meq peroxide on the fifth day with methanol extracts compared to ethyl acetate and chloroform extracts. The methanol, ethyl acetate and chloroform extract of $C$. tuberosus peel inhibit lipid peroxidation greater than the methanol, ethyl acetate and chloroform extract from $C$. tuberosus flesh.

Methanol extract, ethyl acetate extract and chloroform extract of flesh and peel of C. tuberosus, and BHT added to the system can inhibit lipid peroxidation, hence ammonium thiocyanate is formed less. The oxidation of linoleic acid can create free radicals as a result of the incubation process at $40^{\circ} \mathrm{C}$. Free radicals cause the fatty acid to change to lipid peroxide and oxidizes $\mathrm{Fe}^{2+}$ to $\mathrm{Fe}^{3+}$. cations that increase the number of oxidation will react specifically with ammonium thiocyanate, forming ammonium hexothiocyanotoferrate (III) $\left(\mathrm{NH}_{4}\right)_{3}\left[\mathrm{Fe}(\mathrm{SCN})_{6}\right]$ and the color red. The ability of the antioxidant to inhibit oxidation is shown with the least amount of $\mathrm{Fe}^{2+}$ oxidized by peroxide linoleic acid to $\mathrm{Fe}^{3+}$, which is indicated by the decrease in redness intensity. Lipid autooxidation is a chain reaction of free radicals that might be blocked by methanol, ethyl acetate and chloroform extract of flesh and peel of C. tuberosus, therefore, stopping the reaction at the termination stage.

Methanol, ethyl acetate, and chloroform extract of $C$. tuberosus peel can inhibit lipid peroxidation greater than the methanol, ethyl acetate and chloroform extract of $C$. tuberosus flesh. The higher inhibition of the peel extract can be related to the content of the total phenolic content and total flavonoid that was higher than the flesh extract (see Table 1). The difference in the ability of antioxidant activity can also be related to the different content of total phenol and flavonoids in the flesh and peel (Aalolam et al., 2016). Many research has proven that phenol showed antioxidant activity based on FTC method (Gharibi et al., 2013; Yu et al., 2013).

Table 2. The peroxide value on different solvent of the flesh and peel of $C$. tuberosus, BHT and control; incubation on $40^{\circ} \mathrm{C}$, for 5 days (meq peroxide/ $1000 \mathrm{~g}$ of sample)

\begin{tabular}{lcccccc}
\hline \multicolumn{1}{c}{ Solvent } & Zero time & 1 days & 2 days & 3 days & 4 days & 5 days \\
\hline Methanol & $0.07 \pm 0.01^{\mathrm{a}}$ & $0.09 \pm 0.01^{\mathrm{a}}$ & $0.42 \pm 0.03^{\mathrm{b}}$ & $0.52 \pm 0.02^{\mathrm{a}}$ & $0.62 \pm 0.02^{\mathrm{a}}$ & $0.56 \pm 0.06^{\mathrm{a}}$ \\
Ethyl acetate & $0.07 \pm 0.01^{\mathrm{a}}$ & $0.51 \pm 0.04^{\mathrm{d}}$ & $0.73 \pm 0.05^{\mathrm{d}}$ & $1.83 \pm 0.06^{\mathrm{e}}$ & $1.13 \pm 0.08^{\mathrm{c}}$ & $0.78 \pm 0.08^{\mathrm{c}}$ \\
Chloroform & $0.07 \pm 0.01^{\mathrm{a}}$ & $0.32 \pm 0.02^{\mathrm{c}}$ & $0.52 \pm 0.04^{\mathrm{c}}$ & $1.51 \pm 0.07^{\mathrm{d}}$ & $1.26 \pm 0.06^{\mathrm{d}}$ & $1.73 \pm 0.06^{\mathrm{d}}$ \\
\hline \multicolumn{7}{c}{ Flesh } \\
\hline Methanol & $0.07 \pm 0.01^{\mathrm{a}}$ & $0.15 \pm 0.01^{\mathrm{b}}$ & $0.29 \pm 0.00^{\mathrm{ba}}$ & $0.91 \pm 0.05^{\mathrm{b}}$ & $0.79 \pm 0.03^{\mathrm{b}}$ & $0.69 \pm 0.02^{\mathrm{ab}}$ \\
Ethyl acetate & $0.07 \pm 0.01^{\mathrm{a}}$ & $0.41 \pm 0.04^{\mathrm{c}}$ & $0.77 \pm 0.06^{\mathrm{d}}$ & $1.25 \pm 0.05^{\mathrm{c}}$ & $0.87 \pm 0.10^{\mathrm{b}}$ & $0.79 \pm 0.08^{\mathrm{bc}}$ \\
Chloroform & $0.08 \pm 0.01^{\mathrm{a}}$ & $0.52 \pm 0.02^{\mathrm{e}}$ & $1.18 \pm 0.07^{\mathrm{e}}$ & $1.62 \pm 0.06^{\mathrm{f}}$ & $1.52 \pm 0.04^{\mathrm{e}}$ & $1.87 \pm 0.08^{\mathrm{e}}$ \\
BHT & $0.07 \pm 0.01^{\mathrm{a}}$ & $0.33 \pm 0.04^{\mathrm{c}}$ & $0.48 \pm 0.03^{\mathrm{bc}}$ & $0.58 \pm 0.06^{\mathrm{a}}$ & $0.64 \pm 0.05^{\mathrm{a}}$ & $0.72 \pm 0.04^{\mathrm{c}}$ \\
Control & $0.07 \pm 0.01^{\mathrm{a}}$ & $1.08 \pm 0.05^{\mathrm{e}}$ & $1.15 \pm 0.08^{\mathrm{e}}$ & $2.54 \pm 0.07^{\mathrm{f}}$ & $2.89 \pm 0.08^{\mathrm{e}}$ & $2.50 \pm 0.07^{\mathrm{e}}$ \\
\hline
\end{tabular}

Different letters (a-f) within the column indicate significant differences at $\mathrm{P}<0.05$. 
Table 3. TBA value on different solvent of the peel and flesh of C. tuberosus, BHT and control (as mg MDA/1000 g of sample)

\begin{tabular}{lcccccc}
\hline \multicolumn{1}{c}{ Solvent } & Zero time & 1 days & 2 days & 3 dyas & 4 days & 5 days \\
\hline Methanol & $1.39 \pm 0.03^{\mathrm{a}}$ & $2.37 \pm 0.06^{\mathrm{c}}$ & $2.94 \pm 0.06^{\mathrm{b}}$ & $5.31 \pm 0.50^{\mathrm{a}}$ & $5.89 \pm 0.04^{\mathrm{a}}$ & $6.08 \pm 0.02^{\mathrm{a}}$ \\
Ethyl acetate & $1.32 \pm 0.04^{\mathrm{a}}$ & $1.65 \pm 0.07^{\mathrm{b}}$ & $2.45 \pm 0.23^{\mathrm{a}}$ & $8.38 \pm 0.08^{\mathrm{c}}$ & $8.24 \pm 0.05^{\mathrm{c}}$ & $7.47 \pm 0.02^{\mathrm{c}}$ \\
Chloroform & $1.30 \pm 0.6^{\mathrm{a}}$ & $3.55 \pm 0.08^{\mathrm{e}}$ & $3.96 \pm 0.07^{\mathrm{c}}$ & $9.39 \pm 0.20^{\mathrm{e}}$ & $10.20 \pm 0.34^{\mathrm{c}}$ & $8.39 \pm 0.34^{\mathrm{e}}$ \\
\hline \multicolumn{7}{c}{ Flesh } \\
\hline Methanol & $1.36 \pm 0.05^{\mathrm{a}}$ & $2.41 \pm 0.07^{\mathrm{c}}$ & $3.11 \pm 0.07^{\mathrm{b}}$ & $7.14 \pm 0.11^{\mathrm{b}}$ & $8.13 \pm 0.06^{\mathrm{b}}$ & $6.92 \pm 0.03^{\mathrm{b}}$ \\
Ethyl acetate & $1.35 \pm 0.08^{\mathrm{a}}$ & $1.69 \pm 0.03^{\mathrm{b}}$ & $2.24 \pm 0.08^{\mathrm{a}}$ & $8.41 \pm 0.09^{\mathrm{c}}$ & $8.23 \pm 0.04^{\mathrm{c}}$ & $8.08 \pm 0.01^{\mathrm{d}}$ \\
Chloroform & $1.36 \pm 0.05^{\mathrm{a}}$ & $1.35 \pm 0.09^{\mathrm{a}}$ & $4.33 \pm 0.20^{\mathrm{d}}$ & $9.83 \pm 0.09^{\mathrm{f}}$ & $11.78 \pm 0.15^{\mathrm{d}}$ & $9.52 \pm 0.12^{\mathrm{f}}$ \\
BHT & $1.30 \pm 0.05^{\mathrm{a}}$ & $2.72 \pm 0.04^{\mathrm{d}}$ & $3.80 \pm 0.05^{\mathrm{c}}$ & $8.08 \pm 0.07^{\mathrm{d}}$ & $9.71 \pm 0.10^{\mathrm{e}}$ & $7.84 \pm 0.09^{\mathrm{d}}$ \\
Control & $1.32 \pm 0.05^{\mathrm{a}}$ & $4.96 \pm 0.13^{\mathrm{f}}$ & $5.56 \pm 0.16^{\mathrm{e}}$ & $8.05 \pm 0.20^{\mathrm{g}}$ & $11.87 \pm 0.13^{\mathrm{f}}$ & $11.47 \pm 0.13^{\mathrm{g}}$ \\
\hline
\end{tabular}

Different letters (a-f) within the column indicate significant differences at $\mathrm{P}<0.05$.

\subsection{Antioxidant activity evaluation with TBA}

Antioxidant activity of methanol extract, ethyl acetate extract and chloroform extract from the flesh and peel of C. tuberosus and BHT were evaluated using the TBA method. The malondialdehyde of linoleic acid incubated with methanol extract, ethyl acetate extract and chloroform extract from the flesh and the peel, BHT, increased after five days of observation. Table 3 shows that the bioactive compounds extract from methanol solvent for both peel and flesh extract have higher antioxidative capabilities compared to the other solvents.

This research suggests that the antioxidant activity of methanol extract of $C$. tuberosus flesh or peel have the highest antioxidant activity compared ethyl acetate and chloroform extract. However, on the fifth day, the methanol extract of $C$. tuberosus peel and flesh had the lowest mg MDA compared to ethyl acetate and chloroform extract of $C$. tuberosus peel and flesh. The sequence of the inhibitory ability of MDA-TBA is methanol extract $>$ ethyl acetate extract $>$ chloroform extract. The ability to inhibit the formation of the complex MDA-TBA on methanolic extract, ethyl acetate extract and chloroform extract of $C$. tuberosus can be related to the total phenolic and flavonoid content (Table 1). These results were consistent with other research that indicated the content of phenols and flavonoids in the sample could suppress the MDA on the evaluation of antioxidants with TBA (Adebiyiab et al., 2017).

Some research showed that the extract of $C$. tuberosus also contains bioactive compounds such as ursolic acid, oleanolic acid (Nugraheni et al., 2011), maslinic acid, and phytosterol compounds may inhibit peroxidation lipids by suppressing the formation of MDA so that the condensation reaction between the MDA and TBA that form the complex of the MDA-TBA can be hindered (Khennouf et al., 2010). The antioxidant activity difference is related to the difference in the content of bioactive compounds that are located on the peel or the flesh and thus, influence the ability of the formation of the complex MDA-TBA (Jung et al., 2011).

3.5. A correlation between phytochemical compounds with antioxidant activity three methods (DPPH antioxidant, FTC, and TBA)

Table 4. Correlation of bioactive compounds with antioxidant activity

\begin{tabular}{lccc}
\hline \multicolumn{1}{c}{ Parameter } & DPPH & TBA value & Peroxide value \\
\hline Total phenolic & $0.639^{*}$ & $-0.990^{*}$ & $-0.706^{*}$ \\
Total Flavonoids & $0.983^{*}$ & $-0.604^{*}$ & $-0.785^{*}$ \\
DPPH & 1 & $-0.829^{*}$ & $-0.634^{*}$ \\
Peroxide value & $-0.634^{*}$ & $0.692^{*}$ & 1 \\
TBA value & $-0.829^{*}$ & 1 & $0.692^{*}$ \\
\hline
\end{tabular}

* Significant correlation at 0.05 level

There is a correlation between the number of total phenolic and flavonoids on the extracts of C. tuberosus peel and flesh with antioxidant activity. Table 4 shows that the total phenolic and flavonoids have a positive and significant correlation with the DPPH method. This shows the high content of total phenols and flavonoids can increase antioxidant activity with the DPPH method.

The total phenolic content and total flavonoid with TBA and Peroxide value showed a negative and significant correlation. It indicates that higher levels of total phenolic and flavonoids have an impact on the low level of peroxide and TBA value. The low level of peroxide and the TBA value shows that the extract has antioxidant activity. Phenolic compounds have the ability to scavenge free radicals; it is proven by the existence of the strong correlation between the total phenolic content compounds and RSA (Pandey et al., 2017; Shao et al., 2018).

A correlation between the method of determination of antioxidant activity shows that the DPPH have a negative correlation with TBA and peroxide value. A negative correlation indicates that the evaluation of antioxidant activity with the DPPH method is inversely 
proportional to the number and peroxide TBA. A high percentage of DPPH method showed high antioxidant activity. While low peroxide value and TBA value low indicate a high antioxidant activity, related to its ability to inhibit the lipids peroxidation.

\section{Conclusion}

Methanol is shown to extract higher content of total phenolic content, and flavonoid. The methanolic extract has greater antioxidant activity than ethyl acetate extract and chloroform extract on the antioxidant analysis with the DPPH method, peroxide value, and TBA value. The peel of $C$. tuberosus extracted with methanol, ethyl acetate and chloroform have higher total phenolic content, and flavonoid than the flesh of $C$. tuberosus. The peel extract of $C$. tuberosus had higher antioxidant activity compared to the flesh extract based on DPPH, peroxide value and TBA value.

\section{Conflict of interest}

The authors declare no conflict of interest

\section{Acknowledgements}

Authors would like to thank The Directorate General of Higher Education, Ministry of National Education following the Agreement of the implementation of the National Competitive Research Grants number: 180/ SP2H/DP2M/III/2010.

\section{References}

Aalolam, K.P., Nayanathara, A.R. and John, R. (2016). Evaluation of selected fruit peels as natural antioxidant source and to verify the efficacy in increasing the shelf life of commercial paneer. International Journal of Advanced Research, 4(9), 624-629. http://dx.doi.org/10.21474/IJAR01/1527

Adebiyiab, O.E., Olayemib, F.O., Ning-Huaa, T. and Guang-Zhia, Z. (2017). In vitro antioxidant activity, total phenolic and flavonoid contents of ethanol extract of stem and leaf of Grewia carpinifolia. BeniSuef University Journal of Basic and Applied Sciences, 6(1), 10-14.https://doi.org/10.1016/ j.bjbas.2016.12.003

Ahmadi-Alfazi, M., Nybom, H., Ekholm, A., Tahir, I. and Rumpune, K. (2015). Biochemical contents of apple peel and flesh affect level of partial resistance to blue mold. Postharvest Biology and Technology, 110, 173-182. https://doi.org/10.1016/ j.postharvbio.2015.08.008

Arif, H., Sohail, A., Farhan, M., Rehman, A.A., Ahmad, A. and Hadi, S.M. (2018). Flavonoids-induced redox cycling of copper ions leads to generation of reactive oxygen species: A potential role in cancer chemoprevention. International Journal of Biological Macromolecules, 106, 569-578.DOI: 10.1016/j.ijbiomac.2017.08.049

Azmir, J., Zaidul, S.M., Rahman, M.M., Sharifa, K.M., Mohamed, A., Saleha, F., Ahurul, M.H.A.J., Ghafoor, K., Norulaini, N.A.N. and Omar, A.K.M. (2013). Techniques for extraction of bioactive compounds from plant materials: A review. Journal of Food Engineering, 117(4), 426-436. https:// doi.org/10.1016/j.jfoodeng.2013.01.014

Bodoira, R., Rossi, Y., Montenegro, M., Maestri, D. and Velez, A. (2017). Extraction of antioxidant polyphenolic compounds from peanut skin using water-ethanol at high pressure and temperature conditions. The Journal of Supercritical Fluids, 128, 57-65. https://doi.org/10.1016/j.supflu.2017.05.011

Chen, Y., Zhou, S., Wang, Y. and Li, L. (2017). Screening solvents to extract phenol from aqueous solutions by the COSMO-SAC model and extraction process simulation. Fluid Phase Equilibria, 451, 1224. https://doi.org/10.1016/j.fluid.2017.08.007

Do, D.Q., Angkawijaya, E., Tran-Ngyen, P.L., Hyunh, L.H., Soetaredjo, F.E., Suryadilsmadji and Ju, Y.H. (2014). Effect of extraction solvent on total phenol content, total flavonoid content, and antioxidant activity of Limnophila aromatica. Journal of Food and Drug Analysis, 22(3), 296-302. https:// doi.org/10.1016/j.jfda.2013.11.001

Fu, M., Xu, Y., Chen, Y., Wu, J., Bo, Y.Y., Kejing, Z. and Xiao, A.G. (2017). Evaluation of bioactive flavonoids and antioxidant activity in Pericarpium Citri Reticulatae (Citrus reticulata 'Chachi') during storage. Food Chemistry, 230(1), 649-656. https:// doi.org/10.1016/j.foodchem.2017.03.098

Fu, Y., Zhang, Y., Hu, H., Chen, Y., Wang, R., Li, D. and Liu, S. (2014). Design and straightforward synthesis of novel galloyl phytosterols with excellent antioxidant activity. Food Chemistry, 163, 171-177. https://doi.org/ 10.1016/j.foodchem.2014.04.093

Gharibi, S., Tabatabaei, B.E.S., Saeidi, G., Goli, A.H. and Talebi, M. (2013). Total phenolic content and antioxidant activity of three Iranian endemic Achillea species. Industrial Crops and Products, 50, 154-158.

https://doi.org/10.1016/ j.indcrop. 2013.07 .038

Halvorsen, B.L. and Blomhoff R. (2011). Determination of lipid oxidation products in vegetable oils and marine omega-3 supplements. Food and Nutrition Research, 55, 5792.doi: 10.3402/fnr.v55i0.5792

Jung, J.K., Lee, S.U., Kozukue, N., Levin, C.E. and 
Friedman, M. (2011). Distribution of phenolic compounds and antioxidative activities in parts of sweet potato (Ipomoea batatas L.) plants and in home processed roots. Journal of Food Composition and Analysis, 24(1), 29-37. https://doi.org/10.1016/ j.jfca.2010.03.025

Khennouf, S., Amira, S., Arrar, L. and Baghiani, A. (2010). Effect of Some Phenolic Compounds and Quercus Tannins on Lipid Peroxidation. World Applied Sciences Journal, 8(9), 1144-1149.

Mathe, I., Hohmann, J., Janicsak, G. and Redei, D. (2007). Chemical diversity of the biological active ingredients of Salvia officinalis and some closely related species. Acta Pharmaceutica Hungarica, 77 (1), 37-45

Medini, F., Fellah, H., Ksouri, R. and Abdelly. (2014). Total phenolic, flavonoid and tannin contents and antioxidant and antimicrobial activities of organic extracts of shoots of the plant Limonium delicatulum. Journal of Taibah University for Science, 8(3), 216-224. https://doi.org/10.1016/ j.jtusci.2014.01.003

Nugraheni, M., Santoso, U., Suparmo. and Wuryastuti, H. (2011). Potential of Coleus tuberosus as an antioxidant and cancer chemoprevention agent International Food Research Journal, 18(4), 14711480.

Pandey, G., Khatoon, S., Pandey, M.M. and Rawat, A.K.S. (2017). Altitudinal variation of berberine, total phenolics and flavonoid content in Thalictrum foliolosum and their correlation with antimicrobial and antioxidant activities. Journal of Ayurveda and Integrative Medicine. [In Press]. https:// doi.org/10.1016/j.jaim.2017.02.010.

Pintac, D., Majkic, T., Torovic, L., Orcic, D., Beara, I., Simin, N., Mimica-Dukic, N. and Lesjak, M. (2018). Solvent selection for efficient extraction of bioactive compounds from grape pomace. Industrial Crops and Products, 111, 379-390. https://doi.org/10.1016/ j.indcrop.2017.10.038

Prasad, G., Jamkhande, S.K., Pathan, S. and Shailesh, J.W. (2016). In silico PASS analysis and determination of antimycobacterial, antifungal, and antioxidant efficacies of maslinic acid in an extract rich in pentacyclic triterpenoids. International Journal of Mycobacteriology, 5(4), 417-425. https:// doi.org/10.1016/j.ijmyco.2016.06.020

Quettier-Deleu, C., Gressier, B., Vasseur, J., Dine, T., Brunet, J., Luyck, M., Cazin, M., Cazin, J.C., Bailleul, F. and Trotin, F. (2000). Phenolic compounds and antioxidant activities of buckwheat (Fagopyrum esculentum Moench) hulls and flour. Journal of Ethnopharmacology, 72(1-2), 35-40.
https://doi.org/10.1016/S0378-8741(00)00196-3

Raudone, L., Raudonis, R., Liaudanskas, M., Janulis, V. and Viskelis, P. (2017). Phenolic antioxidant profiles in the whole fruit, flesh and peel of apple cultivars grown in Lithuania. Scientia Horticulturae, 216, 186 -192. https://doi.org/10.1016/j.scienta.2017.01.005

Resende, Y.R.R.S., Nogueira, J.P. and Narain, N. (2017). Comparison and optimization of conventional and ultrasound assisted extraction for bioactive compounds and antioxidant activity from agroindustrial acerola (Malpighia emarginata DC) residue. LWT - Food Science and Technology, 85 (Part A), 158-169.https://doi.org/10.1016/ j.lwt.2017.07.020

Saidani, F., Gimenez, R., Aubert, C., Chalot, G., Betran, J.A. and Gogorcena, Y. (2017). Phenolic, sugar and acid profiles and the antioxidant composition in the peel and pulp of peach fruits. Journal of Food Composition and Analysis, 62, 126-133.https:// doi.org/10.1016/j.jfca.2017.04.015

Shao, Y., Hu, Z., Yu, Y., Mou, R., Zhu, Z. and Beta, T. (2018). Phenolic acids, anthocyanins, proanthocyanins, antioxidant activity, minerals and their correlations in non-pigmented, red, and black rice. Food Chemistry, 239, 733-741. https:// doi.org/10.1016/j.foodchem.2017.07.009

Shiraishi, M., Shinomiya, R. and Chijiwa, H. (2018). Varietal differences in polyphenol contents, antioxidant activities and their correlations in table grape cultivars bred in Japan. Scientia Horticulturae, 227, 272-277. https://doi.org/10.1016/ j.scienta.2017.09.032

Singh, R., Singh, B., Singh, S., Kumar, N., Kumar, S. and Arora, S. (2009). Investigation of Ethyl Acetate Extract/fractions of Acacia nilotica Wild. Ex.Del. as potent antioxidant. Record Natural Products, 3(3), 131-138.

Singleton, V.L., Orthofer, R. and Lamuela-Raventos, R.M. (1999). Analysis of total phenols and other oxidation substrates and antioxidants by means of Folin-Ciocalteu reagent. Methods in Enzymology, 299, 152-178. https://doi.org/10.1016/S0076-6879 (99)99017-1

Wang, S.Y., Camp, M.J. and Ehlenfeldt, M.K. (2012). Antioxidant capacity and $\alpha$-glucosidase inhibitory activity in peel and flesh of blueberry (Vaccinium spp.) cultivars. Food Chemistry, 132(4), 1759-1768. https://doi.org/10.1016/j.foodchem.2011.11.134

Wang, X.T., Gong, Y., Zhou, B., Yang, J.J., Cheng, Y., Zhao, J.G. and Qi, M.Y. (2018). Ursolic acid ameliorates oxidative stress, inflammation and fibrosis in diabetic cardiomyopathy rats. 
Biomedicine and Pharmacotherapy, 97, 1461-1467.

DOI: 10.1016/j.biopha.2017.11.032

Yu, R.F., Yi, T.Z., Qiu, R.G., Huang, L., Peng, T., Lin, Y.X. and Chen, T.F. (2013). Antioxidant and antiinflammatory activities of the phenolic extracts of Sapium sebiferum (L.) Roxb. Leaves. Journal of Ethnopharmacology, 147(2), 517-524. https:// doi.org/ 10.1016/j.jep.2013.03.058

Zahin, M., Aqil, F. and Ahmad, I. (2009). The In Vitro Antioxidant Activity and Total Phenolic Content of Four Indian Medicinal Plants. International Journal of Pharmacy and Pharmaceutical Sciences, 1 (Suppl.1), 88-95. 